\title{
Methodological foundations of assessment of the impact of State construction supervision during reprofiling big urban areas
}

\author{
Andrey Tokarsky, ${ }^{1, *}$, Dmitry Topchiy ${ }^{1}$, Sergey Ekba ${ }^{1}$, Vyacheslav Bolgov ${ }^{1}$, and Alexandr \\ Gorochov ${ }^{1}$
}

${ }^{1}$ Moscow State University of Civil Engineering, 26, Yaroslavskoye Shosse, 129337, Moscow, Russia

\begin{abstract}
The stage of construction is one of the main compulsory periods of the life cycle in the formation of construction end-products capital construction projects of various functional purposes. The compulsory assessment of conformity of buildings and structures, as well as design construction, installation, setting up and recycling (demolition) processes associated with buildings and structures is conducted in Russia in the form of state construction supervision. An assessment results in a document certifying conformity of the actual indicators with the requirements of design, normative (industrial) and legislative documents. Conformity is assessed in accordance with procedural rules depending on the functional purpose of the capital construction project. There are two conformity assessment forms that appear to be similar: "construction inspection" and "state construction supervision". They both characterize an approach used to assess the conformity of activities of participants in the construction operations (customers, developers, contractors) on formation of construction end-products - capital construction projects. These terms differ in so far as the construction inspection implies control by the customer of operations of contractors. State construction supervision authorities undertake supervisory (including inspection) activities in order to identify and crack down on violations of the requirements of technological regulations or other normative legal acts and design documents, committed by the key players in the construction investment activities (customer, developer, contractors), with the involvement of state authorities.
\end{abstract}

\section{Introduction}

The primary risk (or rather, man-made risk) associated with the exploitation of the products of construction industry is such a condition (technical, physical) of the objects of capital construction, which may lead to material, social and environmental losses or risks of manifestation of these consequences in the form of accidents or damage.

The account of the possible manifestations of negative consequences associated with the

*Corresponding author: aljurgaitis@gmail.com 
operation of construction projects is based on the quantitative and qualitative indicators that characterize such features of functioning (or properties) of the considered objects of research as "reliability" and "safety". Formation of conditions for the safe and reliable operation is a priority for the objects of capital construction of any functional purpose [1, 2].

Despite the increase of the level of technology of construction processes and the efforts of professionals to improvethe regulatory framework, there has been an increase in the number of accidents on construction sites, as well as the severity of their consequences [3].

The consequences of accidents include: direct economic losses (damage), the shortfall in the profit because of the late commissioning (or loss of part of the calculated capacity) of the construction projects, excessive operating costs; premature physical and moral wearout of construction products, reduction of social and/or environmental conditions [2]. The main causes of accidents are the negative factors of different physical nature, which are formed by or manifest themselves at different stages (periods) in the life cycle of construction projects.

\section{Matherial and methods}

Analysis of accidents happened at the objects of capital construction (of various functional purposes) indicates that the situations caused by accidents are almost never caused by the consequence of the only one reason and occur as a result of interaction of several different factors (or groups of negative factors) [4].

Each of these factors individually may not lead to the accidental consequences, but combined with other adverse factors (which may be formed at earlier stages of the life cycle) lead to accidental impacts.

\subsection{Quality of construction}

The total number of (presently known) individual adverse factors is large enough. It is evident that over time (with an increase of requirements to functional indicators and methods of forming construction products) the number of individual factors will only increase.

In the most general case, under the result of adverse factors (or groups of negative factors) the quality of construction products can be degraded (partialy or completly).

For example, the accident may involve loss of quality which excludes conditions for normal operation of the building object on its initial function. The presence of defects and damages in the constructive system of engineering networks and equipment is characterized as a partial reduction (partial loss) of the quality of the acomplished construction of the facility, which leads to an increase (or contributes to manifestation) of material costs required for the maintenance (repair) of the required performance indicators.

The task of ensuring the quality of construction products implies adequate improvement of the scientific bases, systemic approach, quality management (including monitoring and control) of the of capital construction objects erection [5].

Construction products in the format of buildings and constructions is an object environment of extended (long-term, lifetime-defined) period of use. The extent to which the actual reliability and operational efficiency of the finished construction projects correspond to design and regulatory (legislative acts) values, determines the quality of construction products [6].

The quality construction is one of the key factors determining the viability and prospects of development of this field of economic activity (economy). Ensuring reliability 
and quality is a permanent challenge for the subjects of investment activity in the construction industry.

\subsection{Reasons for violation of construction quality levels}

The formation of the modern major construction objects is characterised by the use of new, progressive materials, structures, and organizational and technological methods of construction. However, the experience of Conformance Inspections performed by the State Construction Supervision organs indicates violations and deviations from the preset quality and indicators of organizational and technological reliability of construction industry. The main reasons for violations of the established construction quality levels are:

- the human factor in the form of construction personnel unqualified and/or characterised by a weak responsibility;

- poor production and laboratory supervision over results of construction processes performed by the Contractor;

- lack of incoming control (with a minimum involvement of objective laboratory analysis) of the quality of construction materials and structures delivered at the construction site;

- poor customers technical control and architectural supervision of design organizations limited in their technical (experimental or laboratory) capabilities.

Lack or insufficient amount of experimental (laboratory) research in the Conformance Inspections implemented by the State Construction Supervision Executive organs form risks of works quality violation and spoilage of construction materials used in the construction process:

- in the implementation of the incoming control of materials, structures and products conformity to requirements of construction norms and regulations, standards, technical conditions and other regulatory documents;

- during the organization and implementation of control and acceptance procedures for the quality assurance of intermediate and hidden construction works that have a direct impact on the construction object reliability;

- during the interaction with the institutions engaged in technical (construction) supervision over construction technology compliance, occupational health and safety compliance, and compliance with the requirements for organization of construction works.

Analysis of conformity of actual framings reliability indicators to their design values (normative or set in the terms of reference) in most cases is not carried out during the construction. It is accepted that the visual lack (or presence within tolerance) of deviations is a characteristic of the used construction products quality which is sufficient to ensure the design values of the reliability indicators. The lack of (or minimal) defects and spoilage occurred during the construction processes can be considered as an important factor in ensuring (improving) the performance of products used in construction.

Early detection of deviations, violations and inconsistencies (in the form of defects, spoilage and fatigue) of framings characteristics allows for an objective and adequate assessment of their technical condition and for development of a deal aimed at preventing the formation and development of the emergency consequences.

The laboratory studies results should be regarded as practical and efficient way of preventing accidents during the construction process and/or during the examination of the possible consequences for violations and preset construction products quality loss. These laboratory studies include assessment of building structures geometric dimensions compliance; analysis of actual values of physical-mechanical, strength, and thermal 
parameters of construction materials; expertise of corrosion resistance, characteristics of fire resistance and environmental safety.

\subsection{Improving the quality of construction}

Improving the quality of construction products is a complex, multifactorial challenge possible with a use of systematic approach along the following main areas (for key subjects in the investment activity in construction) $[7,8]$ :

- improving conditions for the development and effective functioning of the public forms of influence and intervention in the following formats:

- rationing;

- standardization;

- certification;

- licensing;

- state expertise;

- state supervision.

- formation of the necessary conditions for the effective functioning of the non-state forms of influence and intervention in the following formats:

- internal, production control on the part of the contractor;

- architectural supervision by the project organization;

- technical supervision by the customer;

- construction quality control on the part of the investor (insurance companies, banking enterprises, private entities).

Quality of construction products (in the formats of indicators of functional efficiency and reliability) is projected, formed and provided for each of the periods of the life cycle.

Table 1 shows the structure of factors and criteria for the level of quality of construction production. The level of quality largely determines the state (indicators) of competitiveness and is the main factor for the cost of construction products $[7,8,9]$.

Table 1. The structure of factors of influence on construction quality.

\begin{tabular}{|c|c|}
\hline \multicolumn{2}{|c|}{ Determinants of quality of construction production } \\
\hline \multicolumn{2}{|c|}{ Regulations and legislative acts } \\
\hline $\begin{array}{l}\text { - Construction production technology } \\
\text { - Organization of construction production } \\
\text { - Standard of organization } \\
\text { - Quality assessment and control system } \\
\text { - Qualification of management personnel } \\
\text { - Qualification of construction personnel } \\
\text { - Material and non-material factors of } \\
\text { quality stimulation and development }\end{array}$ & $\begin{array}{l}\text { - Efficiency of control of performance of } \\
\text { standards and regulations } \\
\text { - Quality of design solutions and project } \\
\text { documentation } \\
\text { - Quality assurance of building production } \\
\text { - Cost of construction products } \\
\text { - Conditions of financial and material support of } \\
\text { construction production }\end{array}$ \\
\hline \multicolumn{2}{|c|}{ Quality of performance of construction and installation works } \\
\hline Ecc & $\begin{array}{l}\text { Organizational and technical criteria of quality } \\
\text { level }\end{array}$ \\
\hline $\begin{array}{l}\text { - Cost of construction production } \\
\text { - Level (value) of operating costs before the } \\
\text { first repair } \\
\text { - Duration } \\
\text { - Duration of the operating period (lifetime) }\end{array}$ & $\begin{array}{l}\text { - Reliability of the finished construction project } \\
\text { - Finished construction project safety } \\
\text { - Risk minimization of manifestations of defects, } \\
\text { damage to structural elements or fatigue } \\
\text { processes in materials }\end{array}$ \\
\hline
\end{tabular}




\subsubsection{System approach}

Accordingly, the establishment of conditions to achieve the quality of construction products (taking into account possible changes in the provisions of normative and legislative acts) is a complex task. The effective solution of this task is possible under the condition of a systematic approach to the organization of interaction between the main subjects of investment in construction:

"The quality management is the establishment, maintenance and support of the required level of product quality in its development, production and operation, carried out through systematic quality control and a targeted impact on factors affecting quality" [10].

The system approach to quality management of construction products implies the development, approval and execution of a set of measures (technical, technological, economic, organizational work) that accompany the processes of construction.

The development of measures to improve the quality of construction products is carried out in the following main areas:

- timely introduction of changes and additions to the composition of project documentation;

- actualization of provisions of normative and legislative acts;

- development of new types of regulatory documentation that takes into account the current and prospective level of the technological state of the system of construction production;

- improvement of training and enhancing the skills of engineering and construction staff.

Quality management of construction products can be represented in the form of a functional system in which the functions (forecast, planning, organization, control, accounting, analysis, examination, evaluation, licensing, certification) can be considered simultaneously: both as a process and as a result. The function considered as a process is a special kind of management activity and a way of influencing the quality of construction production. The function considered as a result represents an assessment of the level of quality of construction products by the following groups of indicators $[11,12,13]$ :

- rates of purpose;

- indicators of destination;

- indicators of reliability and safety;

- indicators of comfort, ergonomics and environmental friendliness of the environment;

- aesthetics rates;

- technology rates (during erection and operation);

- rates of unification, availability of manufacture;

- information and legal rates;

- economic rates;

- social rates.

A systematic approach to the analysis of violations and discrepancies to design solutions (first of all, framings defects and spoilage) in major construction with the use of acquired inspection statistic data seems a proper way of ensuring performance and safety indicators of both completed and operated construction projects.

The formation and use of specialised database (the State Construction Supervision information system) allow solving the following problems:

- baseline, development and implementation of the concept of reliability and performance indicators control for each of the major phases of the construction object life cycle;

- the formation of the structure of the construction object features and characteristics, justification and specifications of the local conditions required for capability analysis 
(of probability and/or risks) of building structures defects and spoilage appearance and accumulation (primarily those responsible to ensure project reliability and durability);

- review and characteristics of regulatory documents provisions required for making adequate managerial decisions during the design, construction and operation of modern structural and building systems of major construction objects;

- review and description of the scope and performance of existing and promising technologies used in the construction of building structures from the available construction materials;

- analysis and systematisation of the causes and types of building structures defects and spoilage that occur at key phases of construction object life cycle;

- updating of the study and survey findings for structural systems and framing elements of construction objects built and operated in different territories in various climatic and engineering-geological conditions;

- development of reliability and performance indicators predictive assessment methodology (technical condition) which takes into account the quantitative indicators of risks, formation and accumulation of defects and spoilage.

\subsubsection{The quality of data flows}

The key factor for the achievement of construction products quality is the quality of data flows (or potential data) intended to form and modify knowledge of construction investors about the actual condition of the Building Production System, as well as a convenient and efficient way of data exchange.

Data flow of capital construction object is formed at the earliest stages of its life cycle as its symbolic representation or information model. The properties and indicators of both the construction object with related Building Production System and its virtual (information) model become actual as the relevant life cycle periods (phases) pass.

The main features of the technology of major construction object information modelling:

- the model fully represents the features of a particular life cycle period for a particular object of major construction;

- the model includes a certain amount of data determined by the construction regulatory framework and is compulsory in relation to the construction project;

- the results of the accumulation and processing of data at a particular life cycle phase of the construction object are source data for decision-making for subsequent phases.

The main feature of the information modelling technology is the possibility of a multidimensional quality analysis of the accepted (or assumed) constructive, organizational and managerial solutions in virtual mode. This approach allows optimising the composition and amount of required actions focused on the formation of the preset construction products quality.

The formation and use of information technologies gives an opportunity for the qualitative and quantitative growth of performance and quality indicators of major construction objects in the following areas:

- development and improvement of modern concepts considering the interaction of information technologies at all phases of the major construction object life cycle);

- adaptation of effective international approaches and standards to local conditions for the formation of construction objects of different functional purpose;

- the formation of verified and updated data focused on multiple (typical) application of the urban, constructive, organizational, managerial solutions for design, construction and operation of major construction objects in various climatic conditions; 
- establishment and evolutionary change of standards for professional training and improvement of practical skills of professionals working in the construction industry.

Features of data flows formation and means of data collection, analysis and processing are represented in the relevant information systems. For instance, the Urban Development Support Information System (UDSIS).

Information System (UDSIS) is a complex organizational and technical structure consisting of technical, software, information, algorithmic and organizational sub-systems (structural elements). These sub-systems are intended for complex automation and high performance of participants of the construction process in cooperation with the state and local government bodies, authorised in the sphere of urban development:

- software that allows the user to obtain information about a particular aspect of solving a specific design problem. Software can be multi-functional and specialised;

- hardware in the form of physical devices, that is, modern electronic computing machines. Today personal electronic computing machines (PECM) are widely used. Special software of appropriate purposes is developed and being developed for them;

- organizational support and communications in the form of local and wide-area computer networks intended for common user access to the file loading of the information system. Depending on the scope and the specific application features, information systems are characterised by: the complexity of the development and functioning; the automation level of procedures for making and processing of enquiries; the level of complexity; composition and performance.

A systematic approach to data collection and storage (primarily through the creation of relevant databases and algorithms for their analysis) allows to ensure the availability of verified and updated data flows which are necessary to implement the investment, urban planning, and land-use activities with due regard for different stakeholder groups (authorities, agencies, and organizations). Yet it is feasible to form the most of data flows at the local (regional) level and then transfer them to the centralised (state) structure.

Covered information system type allows to organise the interaction between the participants of the construction process (e.g. in urban development) in terms of the formation of construction products volume and quality, including the decisions agreement processes to meet technical requirements for the registration and processing of data.

The participants of the construction process (relevant authorities and institutions) have to analyse composite and individual indicators in order to make adequate managerial decisions. These indicators characterise the following: the level of energy, communication, transport, engineering infrastructure development; geological conditions and the derelict land condition; the functional balance of urban environment; promising directions of the urban environment development.

The full or partial lack of or the uncertainty in information systems data needed for decision-making (in investment projects during the creation of construction products) are characterised by the probability of various risks for the participants of the construction process:

- excessive costs (material and/or financial) required to prepare chapters of the project (including urban planning decisions) and legal (permission) documentation;

- mistakes in chapters of the project documentation and the need of their correction using additional resources which leads to a decrease of construction products investment attractiveness;

- additional financial costs (material costs), organizational and reputational risks of participants of the construction process associated with the uncertainty (or errors in the actual state evaluation) of: building conditions; ensuring the rights and conditions of land use; the availability of local building materials, structures and personnel necessary for material support and human resourcing of established construction processes. 
The establishing of a classified corpus of documented and updated data about actual territory and urban planning conditions (in the UDSIS format) is envisaged by a number of regulations and oriented towards reducing the risks of the construction industry.

Quality analysis of various UDSIS formats developed by now shows that the most successful in giving practical result information systems function in large urban formations.

Covered peculiarities of formation and functioning of UDSIS information systems allows to integrate data flows (verified and updated documentation) of various Building Production System structural elements.

The structure of information system of the UDSIS type can be considered as external in relation to information system characterising the State Construction Supervision activities. It should be noted that the composition of UDSIS has a piece of data which does not exhaust the functional potential of data flows formed on the basis of the State Construction Supervision practical activities. This includes, first of all, identifying violations and inconsistencies of the organizational, technological and design solutions.

\section{Results and discussion}

The current construction quality assurance system is focused only on the methods of construction (technical) oversight and architectural supervision. Today it cannot provide the implementation of increased and fundamentally new requirements to the construction products quality due to the fact that developers, investors and projecting engineers have no necessary organizational and technical (experimental or laboratory) database.

New integrated approaches to ensuring the preset construction products quality (in the form of constant R\&D support of construction) effectively complete the existing control methods through the use of special monitoring tools, systematic imagine and laboratory studies, formation of knowledge and evidence database suitable for the subsequent optimisation of the technological, managerial and organizational solutions.

The formation and updating of data flows in the form of a specialised information system or database is only an additional function and/or the subject of the State Construction Supervision industrial activity. Despite this fact, the development of "inherent" (internal in relation to the main participants of the construction process) multilevel and hierarchically oriented database and knowledge base can be regarded as a powerful analytical method of construction products quality assurance.

The quality level of construction products is expressed by a system (calculated combination) of single (absolute) indicators and / or complex relative index (the ratio of the complex index of quality of construction products to the corresponding complex indicator of the base level).

The quality management is part of a single and integral system for managing construction production and is implemented at each of the possible levels: state, departmental (industrial), production (object). Quality assessment is an indispensable element of any level of management of the product quality system.

At the state level, it is envisaged: planning the necessary indicators and supervising compliance and developing measures to improve the quality of construction products.

Planning the quality of construction products is reduced to the development of regulatory and legislative acts regulating the composition, volume and quality of work and activities performed during the main periods of the life cycle, as well as the establishment of technical conditions for the manufacture of building materials, products and structures.

The supervision of the conformity of the quality of construction products (established in the project documentation) is reduced to conducting checks of compliance by the state construction supervision. In the course of compliance checks, there is provided supervision 
of compliance with safety rules in the performance of construction works and processes, as well as fire, sanitary and epidemiological and environmental safety supervision.

The result of quality management by the state construction supervision is: constant, current, complete and objective assessment of compliance and issuing the recommendations necessary to ensure the established level of quality, regardless of the interests of any subject of investment in construction.

\section{Conclusion}

On the basis of the foregoing, it must be concluded that the modern approach to the activities of state construction supervision based on the criteria of a risk-oriented approach should become the basis for raising the level of quality and safety of construction products at all stages of its formation.

\section{References}

1. A. Tamrazyan, Bulletin of SIC constr. 1, 160-71 (2009)

2. E. Alexandrova, Russia's economic revival 3, 69-76 (2006)

3. D. Topchiy, V. Skakalov, Sci. Prosp. 9, 44-50 (2017)

4. A. Lapina, A. Ponomarenko, K. Chentsova, A. Kotesova, Consr. Mat. and prod. 2, $17-$ 22 (2019)

5. A. Lapidus, Bulletin MGSU 11, 114-23 (2016)

6. S. Mironenko, D. Topchiy, Build. Prod. 2, 52-54 (2013)

7. A. Belov, Sci. and Society 3, 14-17 (2013)

8. Grechishkina Y, Makarova L and Tarasov R 2017 Educ. and sci. in the modern world innov. 3 212-19

9. A. Ort, Russia's economic revival 8, 123-32 (2011)

10. G. Smolyankin, Rus. Bus. 2, 62-65 (2001)

11. A. Ivanov, Fundam. Study 10, 816-19 (2013)

12. A. Efimenko, P. Drozd, Constr. Mater.,equip., technol. of the XXI century 18, 46-48 (2016)

13. E. Zhilkina, Economy and Manag. in the XXI century: develop. trends 3, 106-09 (2013) 